\title{
THERMAL ANNEALING EFFECT ON MORPHOLOGY AND PERFORMANCE OF POLYSULFONE-CELLULOSE ACETATE MEMBRANES: APPLICATION FOR WATER DEFLUORIDATION
}

\author{
HANANE ABURIDEH, ${ }^{* * *}$ NACHIDA KASBADJI MERZOUK, ${ }^{* *}$ MOHAMED WAHIB NACEUR, \\ ZAHIA TIGRINE, ${ }^{* *}$ DJILALI TASSALIT ${ }^{* *}$ and MOHAMED ABBAS ${ }^{* *}$ \\ "Department of Chemical Engineering, Faculty of Technology, University of Blida, \\ PO Box 270, Algeria \\ ** Solar Equipment Development Unit, UDES/Renewable Energies Development Center, CDER, 42004, \\ Tipaza, Algeria \\ 凶Corresponding author: H. Aburideh, h_aburideh@yahoo.fr
}

Received December 25, 2018

\begin{abstract}
The performance of a membrane is a key factor in predicting its reliability. Designing membranes depends on their morphological and molecular characteristics for specific applications. This work focuses on improving the behavior of a cellulose acetate-polysulfone PSf-CA membrane in the presence of PEG 400 additive, in different concentrations, using thermal annealing on the surface of the membrane. The membrane was prepared by the NIPS phase inversion process; the surfaces of the obtained membrane films were subjected to thermal annealing at $75{ }^{\circ} \mathrm{C}$ for 15 seconds. The influence of the composition of the polymer mixture, the concentration of the additive and the annealing effect on the performance of the membranes were studied. The membranes were characterized in terms of contact angle and mechanical resistance, as well as by FTIR, DSC, ATG and SEM. Measurements of the contact angle confirmed the hydrophilic character, which increased with a rising level of PEG in the casting solution. The results showed that the permeation flux increased for the highest PSf/PEG ratio. SEM results suggested that the annealing treatment improved the surface of the membrane; the surface layers became denser and smoother, with a porous intermediate layer, as CA concentrations rose in the mixture. The fluoride reject was evaluated for all the membranes, the obtained fluoride retention rates were very satisfactory and met the standards required by WHO.
\end{abstract}

Keywords: cellulose acetate, phase inversion, membrane, thermal annealing, PEG additive, defluoridation

\section{INTRODUCTION}

Several countries around the world face the problem of saline water and pollutants that affect water quality. ${ }^{1}$ Among these pollutants, fluoride, arsenic and lead of geological origins are most often encountered in groundwater. Excessive fluoride intake is generally caused by the consumption of contaminated groundwater, which may come from the release of toxic industrial wastes into the environment. ${ }^{2}$ This is unfortunately widespread in developing countries and regions where pollution control laws are not enforced. In addition, contaminated water is often consumed without any treatment. ${ }^{3}$

Fluorine does not exist in the free state in nature and is not very abundant in the Earth's crust $(0.028 \%$ of its mass), but is widely distributed. It comes from the dissolution of certain rocks in water. The concentration of fluoride ions in surface water is generally low, at elevated temperature; the physical-chemical characteristics of some salts and groundwater in contact with rock promote the dissolution of minerals containing fluorine. The last ones are several, namely, calcium fluoride (or fluorine) $\mathrm{CaF}_{2}$, fluorite (or fluorspar), cryolite $\left(\mathrm{Na}_{3}\left(\mathrm{AlF}_{6}\right)\right)$, biotite $\quad\left((\mathrm{Mg}, \quad \mathrm{Fe})_{2} \mathrm{Al}_{2}(\mathrm{~K}, \mathrm{H}) \quad(\mathrm{SiO} 4)_{2}\right) \quad$ or fluorapatite $\mathrm{Ca}_{5}\left[\mathrm{FCl}(\mathrm{PO} 4)_{3}\right]$.

In Africa, several countries are affected by the problem of excess fluoride in water: Senegal, ${ }^{1}$ Morocco, ${ }^{5}$ Malawi, ${ }^{6}$ Algeria $^{7}$ and Tunisia. $^{8}$ Youcef et al. ${ }^{9}$ have carried out analyses on samples taken from the east northern Sahara (see 
Table 1). They noted that some waters only slightly exceed international standards. However, these waters constitute the only source of drinking water, and as the hot and dry climate forces the inhabitants to consume a lot of water, the amount of fluorine absorbed by the body increases daily. As a result, the treatment of fluoridated water becomes essential. It should be noted that there are no stations in Algeria for this purpose.

Because of the adverse effects of fluoride, it is essential to develop an appropriate method for the removal of fluoride from water. Different treatment technologies applied for fluoride elimination have been classified into three categories, namely: adsorption, ${ }^{10}$ ion precipitation $^{11} /$ co-precipitation ${ }^{12}$ and membrane technology. ${ }^{13-15}$

According to the literature, researchers have studied the phenomenon of fluoride removal using the membrane filtration technique. Pontie et $a l .{ }^{14}$ have studied a phenomenological mass transfer in nanofiltration for a selective defluorination of brackish drinking water in Niakhar, Senegal (Thiès region). The obtained results of combined reverse osmosis with nanofiltration indicate better demineralization than that achieved by reverse osmosis. ${ }^{15}$ They found that nanofiltration allows carrying out, in only one stage, the fluoridation and the total sterilization of fluoride-rich brackish water and no remineralization appears necessary after the treatment. They proved that nanofiltration was the most appropriate technique for the purification of brackish water. The energy demand of this installation is of the order of $2.2 \mathrm{kwh} / \mathrm{m}^{3}$ powered by photovoltaic systems.

In 2011, Lhassani et al. ${ }^{16}$ used the nanofiltration process (NF) for defluoridation of groundwater in southern Morocco, which has a high concentration of salt and ion fluoride. They used industrial membranes (NF90 and BW30), which are made from thin film composite materials (TFC) using a polyamide skin layer with a surface of $7.6 \mathrm{~m}^{2}$. The experimental tests were carried out in the batch mode, with pressure ranging from 0 to 20 bar. The study showed that the treatment using the NF90 system was more effective than that with BW30, because it can partially reduce total salinity and the high fluoride content for a higher return flow $(70 \%)$ and a lower pressure (twice less than with BW30).

This research has confirmed that, on a large scale, the performance of nanofiltration offers better selectivity for water defluoridation. This opens up broad prospects for highlighting the manufacture of membranes, encouraging research laboratories to show great interest in membranes and definitively solve the problem of defluoridation. It is therefore very important to improve and develop effective methods to optimize the performance of existing membranes and develop new membranes characterized by high throughput, good rejection and maximum selectivity using materials and methods that respect the environment. ${ }^{17,18}$

The phase inversion method is historically the reference technique for the manufacture of organic membranes. ${ }^{19}$ Even today, it is the method chosen by the industry to manufacture the majority of flat membranes and hollow fibers. It allows the development of membranes that cover the entire range of filtration, from $\mathrm{MF}$ to OI. ${ }^{20}$ The production of a membrane by phase inversion requires the dissolution of the constituent polymers of the future membrane and additives in a solvent mixture(s): the collodion is obtained. ${ }^{21}$

The chemical nature of the membrane and its geometry are dependent on the nature of the polymers used, a large variety of polymers contributing to the manufacture of membranes, including polypropylene (PP), polytetrafluoroethylene (PTFE), polyvinylidene fluoride (PVDF) and polyvinyl chloride (PVC), cellulose acetate (CA), polysulfone (PSf), polyether sulfone (PES) and polyacrylonitrile (PAN).

However, certain polymers are hydrophobic or slightly hydrophilic and are therefore a priori susceptible to clogging. The addition of additives to the solution is necessary and gives the membranes singular properties and, in particular, surface, structural and material transfer properties. Numerous additives have been used in this sense, such as inorganic salts, oligomers, polymers, surfactants, copolymers, (nano)metal or ceramic particles and carbon nanotubes. $^{22}$

\section{A review on CA/PSF membranes for water treatment}

Membrane filtration is one of the modern processes developed in recent years worldwide in several fields, including the treatment of different types of water, including seawater, brackish water, used water, etc. It has proven its reliability and is implemented on a commercial and industrial scale. ${ }^{18}$ Historically, the first filtration membranes were developed in the 1930s; William Elford was a pioneer in their use in the medical 
field. He made membranes from cellulose acetate and cellulose nitrate to filter viral solutions. ${ }^{22}$ One of the first "industrial" uses for water purification was carried out in Germany during the Second
World War. The system made it possible to produce drinking water for the soldiers in the battle area.

Table 1

Levels of fluoride in water samples from southern Algeria ${ }^{9}$ and effect of prolonged consumption of drinking water on human health, related to fluoride content ${ }^{31}$

\begin{tabular}{lccc}
\hline \multirow{2}{*}{ Town } & $\begin{array}{c}\text { Fluoride content in } \\
\text { groundwater, } \mathrm{mg} / \mathrm{L}\end{array}$ & $\begin{array}{c}\text { Fluoride content in } \\
\text { Albian water, mg/L }\end{array}$ & $\mathrm{F}, \mathrm{mg} / \mathrm{L}$, impact on health \\
\cline { 4 - 4 } & $1.00-2.15$ & $1.90-4.55$ & $<0.5$ Dental caries \\
El-Oued & $1.00-2.15$ & $1.00-2.20$ & $0.5-1.5$ Optimum dental health \\
Biskra & $1.95-2.20$ & $1.75-2.10$ & $1.5-4.0$ Dental fluorosis \\
Ghardaia & $1.10-1.25$ & $0.2-1.30$ & $4.0-10$ Dental and skeletal fluorosis \\
\end{tabular}

Cellulose acetate (CA) is considered an environmentally friendly and inexpensive hydrophilic biopolymer; it is characterized by availability, widespread application and resistance to clogging and chlorine. ${ }^{23-24}$ It has been widely used to develop reverse osmosis (RO), ${ }^{25}$ nanofiltration (NF), ${ }^{26}$ ultrafiltration (UF) ${ }^{27}$ and microfiltration $(\mathrm{MF})^{28-29}$ membranes by the standard phase reversal method and has been the subject of several studies. ${ }^{30}$ The disadvantage of cellulose acetate membranes is that they are sensitive to chemical agents (high $\mathrm{pH}$, temperature, oxidants) and have low mechanical strength. Polysulfone PSf is a widely used membrane material due to its many advantages, its chemical and mechanical resistance, and its application in a wide $\mathrm{pH}$ range of $\mathrm{pH} 2-12$. Its major drawback lies in its hydrophobic character, which leads to low water flow and risk of clogging. ${ }^{31}$

Taking into account the advantages and disadvantages of polysulfone and CA, several studies have been conducted on PSf/CA mixtures in order to obtain membranes with optimal properties, specifically, a long life, hydrophilic nature and little clogging. ${ }^{32}$ The various methods used are subdivided into three different classes. ${ }^{33}$ The first is the addition of hydrophilic or organic materials, such as polyvinylpyrrolidone (PVP) ${ }^{34}$ or with certain minerals, such as zirconium dioxide $(\mathrm{ZrO} 2),{ }^{35}$ the second corresponds to a coating with hydrophilic polymers, ${ }^{36}$ and the third class describes grafting with hydrophilic polymers or monomers. ${ }^{37-39}$ Abdullah et al. ${ }^{23}$ studied mixtures of cellulose acetate (CA) and polysulfone (PSf) dissolved in $\mathrm{N}, \mathrm{N}$ dimethylacetamide (DMAc) as a solvent and polyvinylpyrrolidone (PVP) as an additive. The highest flow rate was observed for the mixture CA/PSf: $75 / 25$ of $9.93 \mathrm{~L} / \mathrm{m}^{2} \mathrm{~h}$, while the lowest flux was recorded for the membrane CA/PSf: $100 / 0$, of $7.16 \mathrm{~L} / \mathrm{m}^{2} \mathrm{~h}$. The rejection of the salt $(\mathrm{NaCl})$ also increased with the decrease of the CA composition in the mixed polymer. The best performance was obtained for the following formula: $25 \% \mathrm{PSf} 7.5 \% \mathrm{PVP}$ and $75 \% \mathrm{CA}^{37}$

M. Sivakumar et $a l .{ }^{40}$ noted that the increase in the polysulfone content in CA-PSf mixtures resulted in an increase in the flow of pure water and in the water content. The rejection of the BSA was higher, compared to a smaller flow. Phase separation occurred above $25 \%$ by weight of polysulfone in the mixture. In another work, Sivakumar et $a .^{41}$ studied the effect of adding polyethylene glycol (PEG) in the PSf/CA mixture at different concentrations. Their results showed that the PSF-CA mixture at $0 \%$ by weight of PEG had a lower flow rate of $9.8 \mathrm{~L} / \mathrm{m}^{2} \mathrm{~h}^{-1}$. Increasing the PEG 600 content in the PSf/CA mixture from 2.5 to $12.5 \mathrm{wt} \%$ increased the flux from 24.4 to $74.0 \mathrm{~L} / \mathrm{m}^{2} \mathrm{~h}$. They have proved that the addition of PEG 600 in the mixture increases not only the hydrophilic behavior, but also the macrophase separation of the membrane mixture.

The annealing temperatures have been studied in order to tighten the pores of the membrane and to thus pass from UF to NF by modifying the morphology of the membrane. Said et al. ${ }^{42}$ studied PSf 19\% DMFEVA2 membranes without annealing and PSf $19 \%$ DMFEVA2T75 with 75 ${ }^{\circ} \mathrm{C}$ annealing. They found that the pore stability of the annealed membrane becomes higher and the pore size of the membrane will be more uniform than that of the non-annealed counterparts. The 
membranes were tested for the treatment of the liquid waste of a palm oil mill (POM). The PSf 19\% DMFEVA2T75 membrane had a higher rejection value, with an optimal rejection of 97.42\%, compared to the PSf $19 \%$ DMFEVA2 annealed membrane. They deduced that the pores of the membrane are much more stable and the degree of swelling on the pores of the membrane is much smaller, so that its solubility rate is much lower than that of an unannealed membrane, and therefore it is considered more effective for POM wastewater purification.

The performance of the cellulose acetate (CA) membrane annealed in a bath at $80{ }^{\circ} \mathrm{C}$ for $15 \mathrm{~min}$ was evaluated by Zyaie et al., ${ }^{30}$ using a reverse osmosis (RO) set-up. The best results were obtained for the membrane prepared under the influence of an annealing treatment with a concentration of $20 \% \mathrm{CA}$ at a coagulation bath temperature (CBT) of $23{ }^{\circ} \mathrm{C}$. This membrane gave the optimal rejection in $\mathrm{NaCl}$ of $76 \%$, a water flow (WF) of $21.75 \mathrm{~L} / \mathrm{m}^{2} \mathrm{~h}$ and the flux of inverse solute (RSF) of $5.88 \mathrm{~g} \cdot \mathrm{m}^{2} \mathrm{~h}^{-1}$. They also deduced that the annealing treatment led to the formation of a contracted and denser external surface morphology, with a less porous structure.

Other cellulose acetate membranes were prepared by phase inversion, with annealing at two temperatures of 70 and $75{ }^{\circ} \mathrm{C}$, at evaporation times of 20, 30 and 60 seconds. The pure water flux tests classified CA620-70, CA630-70, CA660-70 and CA620-75 as ultrafiltration (UF) membranes, and CA630-75 and CA660-75 as nanofiltration (NF) membranes. The rejection of the BSA protein is $100 \%$ and that of tannin varies between $78-100 \%$, the mechanical resistance of the membrane was measured, they obtained a tensile strength from 1.64 to $2.82 \mathrm{~N}$, an elongation at break from 15.57 to $23.00 \%$ and Young's modulus from 54.74 to $175.36 \mathrm{MPa}^{43}$

Kusworo et $\mathrm{al}^{28}$ subjected the surfaces of membrane prepared from cellulose acetate (CA) and PEG as additives in different concentrations, to annealing temperatures at 60 and $70{ }^{\circ} \mathrm{C}$ for 5 , 10 and 15 seconds. They found that the membrane became denser and more compact and membrane rejection increased significantly, while the flux was slightly decreased. The best membrane performances are obtained with $18 \%$ by weight cellulose acetate and $5 \%$ by weight polyethylene glycol, with thermal annealing at $70{ }^{\circ} \mathrm{C}$ for 15 seconds.

Based on the above studies, it can be seen that the use of thermal annealing by modifying the morphology of the membrane has enormous advantages over the performance of the membrane. In this context, we have been interested in working in this direction; our job has been to combine PSf and CA to take the advantages of each polymer and compensate for the disadvantages of one by the other. The membranes were prepared by the NIPS phase inversion method using thermal annealing at 75 ${ }^{\circ} \mathrm{C}$ and adding PEG additive. The performances of the membranes obtained have been tested to treat water rich in fluoride, which causes serious health problems and affects areas in the southern Algerian Sahara (Table 1). Substantial research and development efforts have been made worldwide to reduce fluoride levels to acceptable limits (Table 1) demanded by the World Health Organization. Long ago, this organization (WHO, 1984) estimated that more than 260 million people in the world consumed drinking water with a fluoride content $>1.0 \mathrm{mg} / \mathrm{L}$. These people live in tropical countries, where this problem is exacerbated by the need to drink more water because of the heat. ${ }^{45}$

\section{EXPERIMENTAL \\ Materials}

Cellulose acetate $\left(\mathrm{M}_{\mathrm{n}} 50.000\right.$ BY GPC Cas 9004$35-7$ d $1.3 \mathrm{~g} / \mathrm{mL}$ ) (Germany), polyethylene glycol $(\mathrm{PEG}$, Ultrason S 2010, MW $=400 \mathrm{Da})$ and polysulfone (PS, Ultrason E $6020 \mathrm{P}, \mathrm{MW}=51,000 \mathrm{Da})$ were purchased from Sigma Aldrich (Germany). The solvent $\mathrm{N}, \mathrm{N}$-dimethylformamide (DMF) was selected for this work, because it was regarded as a good solvent in several polymers. Sodium fluoride NaF201145-5G Sigma Aldrich Cas 7681-49-4 was used for the preparation of fluoride solutions with different ratios. All the chemical reagents used in this work were of analytical grade; they were used as received, without further purification.

\section{Polymer blend preparation}

The membranes were prepared by the NIPS (nonsolvent induced phase separation) phase inversion method. The polymer blend solutions $(17.5 \%$ by weight) were prepared by mixing polysulfone PSf with cellulose acetate CA with different compositions in DMF for $4 \mathrm{~h}$ at $90{ }^{\circ} \mathrm{C}$, and in the presence of PEG as additive, with constant stirring of $500 \mathrm{rpm}^{23,41-42}$

A homogeneous solution was obtained and then left without stirring for 30 minutes to remove air bubbles. The homogeneous casting solutions were spread on a glass plate, using a casting knife with a thickness of $250 \mu \mathrm{m}$. After evaporation for 30 seconds, the films were immersed in a coagulation bath at $4{ }^{\circ} \mathrm{C}$, then 
annealed in an oven at $75{ }^{\circ} \mathrm{C}$ for 30 seconds. ${ }^{30,44}$ All the membranes were stored in distilled water.

The casting compositions of the membranes are shown in Table 2 and the structure of the mixture components is illustrated in Figure 1. The casting solution became cloudy and the mixture was not homogeneous at a polysulfone concentration of $30 \%$, which allowed concluding that the optimal composition of PSf is $25 \%$.

Table 2

Composition of PSF/PEG/AC blend membranes

\begin{tabular}{lcccccccc}
\hline Code & PSf & PEG & AC & $\begin{array}{c}\text { Solution } \\
\text { observation }\end{array}$ & $\begin{array}{c}\text { Film } \\
\text { quality }\end{array}$ & $\begin{array}{c}\text { Contact } \\
\text { angle }\left({ }^{\circ}\right)\end{array}$ & $\begin{array}{c}\% \text { Water } \\
\text { uptake }\end{array}$ & $\begin{array}{c}\text { Water permeability } \\
\left(\mathrm{L} / \mathrm{m}^{2} \mathrm{~h} . \mathrm{bar}\right)\end{array}$ \\
\hline MA & 15 & 10 & 75 & Homogeneous & ++ & $61 \pm 2$ & 74 & 3.7457 \\
MB & 30 & 10 & 60 & Heterogeneous & -- & -- & -- & -- \\
MC & 25 & 12 & 63 & Homogeneous & ++ & $60 \pm 2$ & 72 & 4.0033 \\
MD & 40 & 20 & 40 & Heterogeneous & -- & -- & -- & -- \\
ME & 5 & 5 & 90 & Homogeneous & ++ & $65 \pm 1$ & 71 & 1.3506 \\
MF & 10 & 15 & 75 & Homogeneous & ++ & $69 \pm 2$ & 72 & 1.2342 \\
MG & 0 & 10 & 90 & Homogeneous & ++ & $62 \pm 4$ & 67 & 0.8357 \\
MH & 10 & 0 & 90 & Homogeneous & ++ & $74 \pm 4$ & 70 & 0.7991 \\
\hline
\end{tabular}

++ Very good film

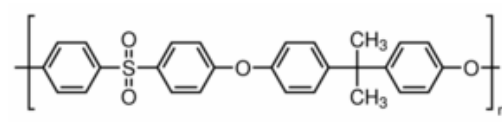

Polysulfone (PSf)

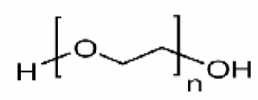

Polyethylene glycol (PEG)

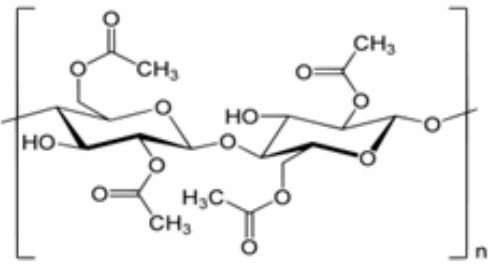

Cellulose acetate (CA)

Figure 1: Structure of blend components: polysulfone (PSf), polyethylene glycol (PEG) and cellulose acetate (CA)

\section{Membrane characterization}

The membrane films were characterized by DSC/ATG, FTIR and SEM, as well as in terms of mechanical resistance, water uptake and contact angle.

\section{Thermal analysis}

The membrane was analyzed by differential scanning calorimetry (DSC)/thermogravimetric analyseis (TGA), using a Universal V4.5A TA Instruments. The heating rate was $20^{\circ} \mathrm{C} / \mathrm{min}$, from 0 to $800{ }^{\circ} \mathrm{C}$ under nitrogen atmosphere.

\section{Fourier transform-infrared spectroscopy (FTIR)}

Infrared spectroscopy is the analysis of the chemical structure of a polymer. The energies of the vibrations of chemical bonds measured identify the nature of the functional groups present in the sample. A Bruker (ALPHA) Fourier transform infrared spectrometer was used. The frequency range varied from 375 to $7500 \mathrm{~cm}^{-1}$.

\section{SEM analysis}

The cross-sections of the membranes were examined after coating with fine gold under reduced pressure, using a Zeiss-EVO Ma 10 scanning electron microscope (Oberkochen, Germany).

\section{Mechanical properties}

The mechanical strength of the plane membranes was determined against longitudinal (uni-axial) tensile stress, using a Zwick/Roell INSTRON 3342 Series tensile tester.

\section{Contact angle}

The hydrophilic properties of the surface of the membranes were assessed by measuring the contact angles at $20{ }^{\circ} \mathrm{C}$. Contact angle measurements were 
performed using a CAM 100 instrument optical tensiometer, Nordtest SRL, GI, via the drop method.

\section{Membrane performance \\ Water uptake}

To obtain the weight of the wetted membrane, the membrane films were soaked in water for $24 \mathrm{~h}$, dried with paper and weighed. They were then dried in an oven at a temperature of $80{ }^{\circ} \mathrm{C}$ for 24 hours and then weighed again to obtain the weight of the dry membrane. From three measurements, the percentage of water uptake was calculated by the following equation: ${ }^{40-41}$

Water up take $(\%)=\frac{\mathrm{Ww}-\mathrm{Wd}}{\mathrm{Wd}} 100$

where $\mathrm{W}_{\mathrm{w}}$ is the wet membrane's weight, $\mathrm{W}_{\mathrm{d}}$ is the dry membrane's weight.

\section{Filtration system}

The water permeation properties of the polymeric membranes were tested using a lab-made cross-flow filtration apparatus at room temperature. Figure 2 illustrates the scheme of the filtration set-up (a) and a picture of the membrane filtration system used (b).

The set-up is equipped with a high pressure pump, a flat sheet membrane module with three feed openings, concentrate and permeate. Two valves located at the outlet can be adjusted and allow reading the pressure exerted. The performance tests were

carried out at ambient temperature under a pressure, which varies from 2-20 bar and the surface of the membrane in the cell is of the order of $64 \mathrm{~cm}^{2}$.

Equations (2) and (3) measure the flux of pure water known as pure water permeability (PWF) and that of the solutions to be treated: ${ }^{29,43}$

$J_{W}=\frac{Q}{A \Delta t}$

where $J_{\mathrm{w}}$ is the pure water permeation flux $\left(\mathrm{Lm}^{-2} \mathrm{~h}^{-1}\right)$, $\mathrm{Q}$ is the amount of permeate in $\mathrm{L}, \mathrm{A}$ is the effective membrane surface area $\left(\mathrm{m}^{2}\right)$ and $\Delta \mathrm{t}$ is the time $(\mathrm{h})$.

Hydraulic permeability $\left(\mathrm{R}_{\mathrm{m}}\right)$ was obtained from the slope of the plot of $\mathrm{J}_{\mathrm{W}}$ and $\Delta \mathrm{P}$ and was calculated by:

$R_{M}=\frac{J_{W}}{\Delta P}$

Synthetic sodium fluoride solutions (NAF) were prepared in the laboratory with different sodium fluoride concentrations $(2.47 \mathrm{mg} / \mathrm{L}, 4.67 \mathrm{mg} / \mathrm{L}, 8.62$ $\mathrm{mg} / \mathrm{L}$ ) and were tested to study the rejection and the performance of the membrane. The concentration of fluoride was evaluated using a Metrhom $781 \mathrm{pH}$-ion meter (ionimeter). The rejection of fluoride ions was calculated using Equation (4) shown below:

$R(\%)=\left(1-\frac{C_{p}}{C_{f}}\right) 100$

where $\mathrm{C}_{\mathrm{p}}$ and $\mathrm{C}_{\mathrm{f}}$ are the concentrations of fluoride in permeate and feed, respectively.

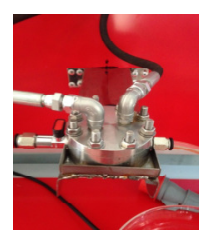

Filtration cell

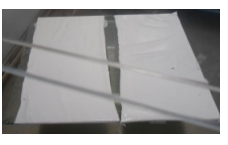

Flat membrane

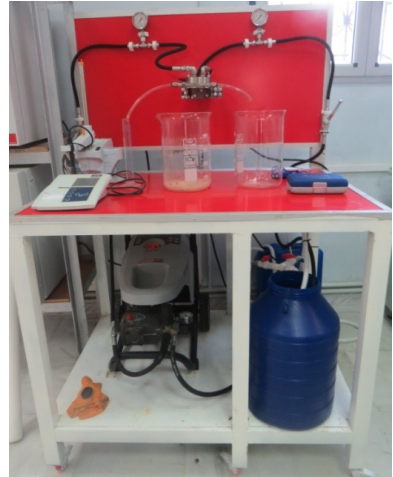

b)

Figure 2: Scheme of filtration set-up (a) and picture of the membrane filtration system used (b)

\section{RESULTS AND DISCUSSION Thermal analysis}

We studied the thermal stability of PSf/CA composite membranes by thermogravimetric analysis to determine their degradation temperature. Figure 3 shows the evolution of the membrane weight percent as a function of temperature. A small mass loss was observed around $95{ }^{\circ} \mathrm{C}$, attributed to the evaporation of water traces and solvents from all the membranes. The second loss corresponds to the degradation of the cellulose acetate and it is situated between
330-350 ${ }^{\circ} \mathrm{C}$. This weight loss varies from one membrane to another, the largest being observed for the membranes $\mathrm{G}, \mathrm{H}$ and $\mathrm{E}$, which correspond to higher cellulose weight of $90 \%$. The last loss is around $460-500{ }^{\circ} \mathrm{C}$ for all the membranes, with the exception of membrane $\mathrm{G}$ ( $0 \%$ polysulfone). This is explained by the degradation of polysulfone. The mass losses recorded vary between 6-11\%. From an application point of view, it should be noted that the temperature corresponding to $1 \%$ degradation of the mass of a membrane (denoted $\mathrm{T}_{\mathrm{deg}}, 1 \%$ ) is chosen as the 
temperature under which the degradation of the material starts. This temperature value is higher than $\mathrm{T}=200{ }^{\circ} \mathrm{C}$ for all the flat membranes. We note that this temperature is higher than the maximum temperature used for water treatment by membrane separation. ${ }^{48}$

The DSC technique was used to evaluate the thermal stability and miscibility of membrane mixtures (Fig. 4). Reported $\mathrm{Tg}$ values for polysulfone and cellulose acetate are from $180{ }^{\circ} \mathrm{C}$ to $200{ }^{\circ} \mathrm{C}$.

The DSC curve for the PSf/CA membrane mixtures with different concentrations showed a single glass transition temperature $\mathrm{Tg}$. It reflects the miscibility of the mixture components over

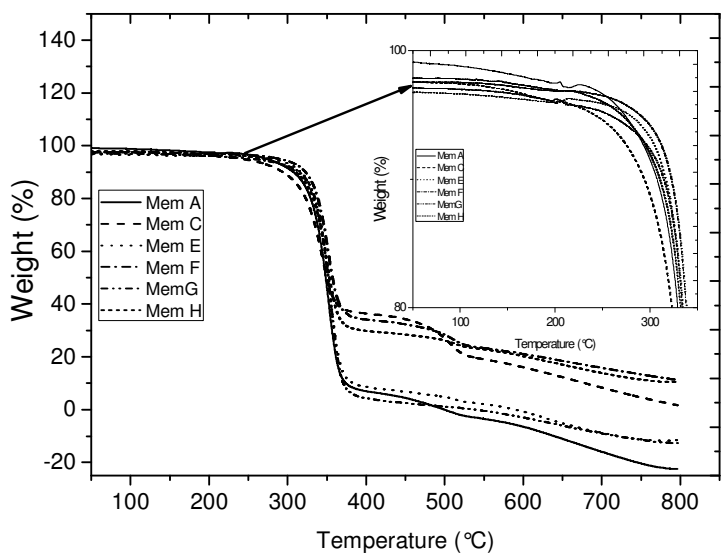

Figure 3: TGA curves of membrane films
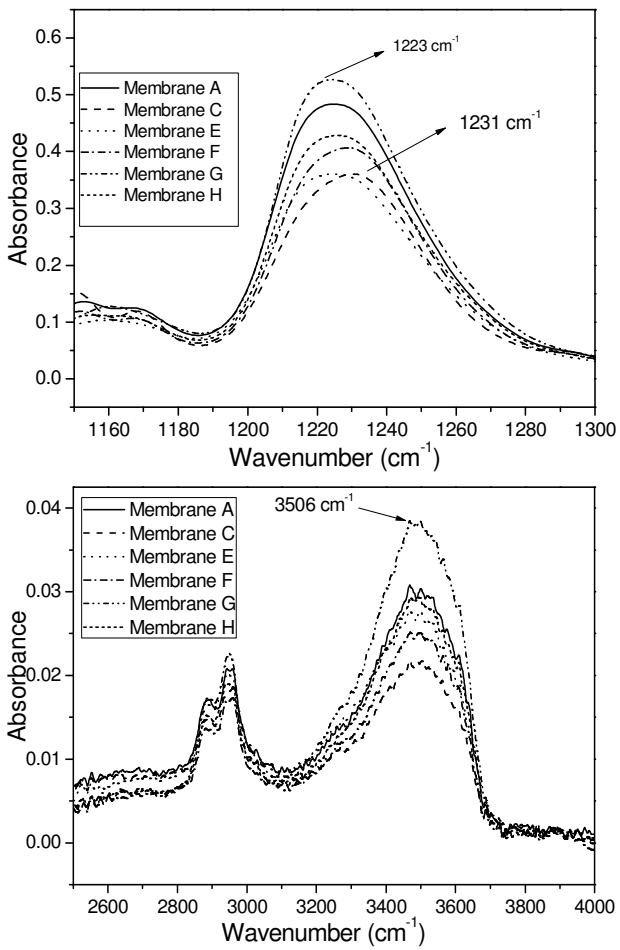

Figure 5: FTIR spectra of membranes containing PSf-AC

the entire range of the concentrations studied. In addition, it is superior to that of the virgin polymers PSf and CA, which is explained by the appearance of a new intense specific interaction between the two components of the polymer. ${ }^{48-49}$

\section{FTIR analysis of membranes}

The FTIR spectra of all the membranes reveal the absorption peaks of all the intra- or intermolecular bonds, that is, the interactions that exist between the functional groups within each component or can be formed between different components in a mixture, which may help in predicting their miscibility.

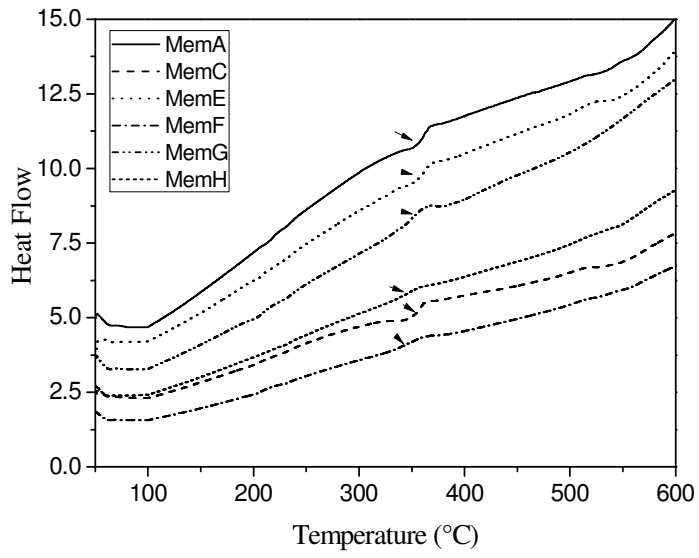

Figure 4: DSC curves of membrane films
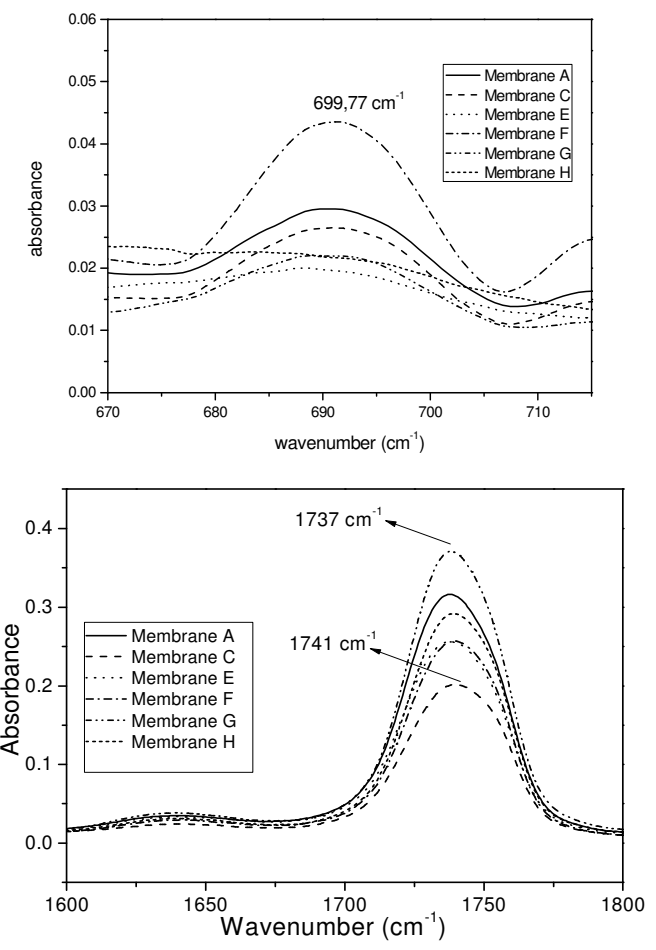
Concerning polysulfone PSf, several peaks are observed in Figure 5, the most important being the bands at 1250 and $1050 \mathrm{~cm}^{-1}$, signifying the symmetric stretching vibration of $\mathrm{O}=\mathrm{S}=\mathrm{O}$ groups, confirming the presence of vs (SO3) and vas (SO3), respectively.

The bands at 2874, 2970 and $3096 \mathrm{~cm}^{-1}$ indicate the presence of asymmetric and symmetric $\mathrm{C}-\mathrm{H}$ stretching vibrations, involving the entire methyl group and $\mathrm{CH}$ aromatic stretching, respectively. ${ }^{50}$ The intensity of these bands increases by increasing the polysulfone molecular weight.

On the other hand, the cellulose acetate ${ }^{51}$ was characterized by the absorption band of $\mathrm{C}=\mathrm{O}$ observed at $1730 \mathrm{~cm}^{-1}$ and by the peak at 3500 $\mathrm{cm}^{-1}$, attributed to the $\mathrm{O}-\mathrm{H}$ stretching band. It is wider and more intense for membrane $G$, containing $90 \%$ by weight of CA, and decreases with decreasing CA concetration in the mixture (Fig. 5). The aliphatic $\mathrm{C}-\mathrm{H}$ stretching absorption bands are numerous, as illustrated in the following regions 2901, 1442, 1374 and 1339 $\mathrm{cm}^{-1}$. The deformations in the $\mathrm{C}-\mathrm{H}$ plane and $\mathrm{O}-\mathrm{H}$ were observed at 998 and $1214 \mathrm{~cm}^{-1}$. The vibrations of the $\mathrm{C}-\mathrm{O}$ and $\mathrm{C}-\mathrm{C}$ groups correspond to the peaks at 554 to $1145 \mathrm{~cm}^{-1}$.

The characteristic band of the $\mathrm{CH} 2 \mathrm{OH}$ groups, characteristic of PEG, was observed at $691 \mathrm{~cm}^{-1}$, confirming the presence of PEG in the membrane structure of MA, MC, ME, MF and MH. The most intense peak was observed for membrane $\mathrm{F}$, which contains $15 \%$ by weight of PEG, decreasing as the content of PEG decreases in the mixture. ${ }^{52}$ The absence of the peak was noted for the membrane $\mathrm{G}$, which does not contain PEG. We also noted that it becomes important as PEG increases in the mixture. This flexible group reduces the rigidity of the chain, thus decreasing their glass transition. ${ }^{53}$ This confirms the results obtained by DSC.

In addition, we noted the enlargement and a shift of the CA peaks observed at $1223 \mathrm{~cm}^{-1}$ and $1730 \mathrm{~cm}^{-1}$ to higher wavenumbers of $1231 \mathrm{~cm}^{-1}$ and $1741 \mathrm{~cm}^{-1}$, respectively, thus indicating the presence of new bonds between the mixture components, confirming their miscibility.

\section{SEM analysis}

The performance of asymmetric membranes depends on many factors, such as the structure and geometric characteristics, as well as the effect of annealing on the morphology of the membrane. To evaluate the morphology of the membranes, the cross-sections of different membranes were characterized by SEM. Figure 6 illustrates the cross-section of different membranes with different PSf/CA ratios.

The SEM images of different asymmetric membranes annealed at the temperature of $80{ }^{\circ} \mathrm{C}$ for 30 seconds show a dense upper skin layer, which is thicker for the cellulose acetate-rich membranes, such as membranes $\mathrm{H}$ and $\mathrm{G}$. This is explained by the movement of molecules in the polymer chains, which becomes easier and affects the morphological structure of the membrane. In addition, this causes a decrease in the free volume formed in the membrane, following the heat treatment, thereby causing the narrowing of the pores and, consequently, a more dense morphology. ${ }^{30,44}$

The images (a) show that membrane $\mathrm{C}$, containing a low concentration of CA (63\%-70\%) and a high PSf/PEG ratio, has in the intermediate layer finger-like macrovoids and a porous spongelike structure. It is attributed to the domination of instantaneous and delayed demixing, respectively.

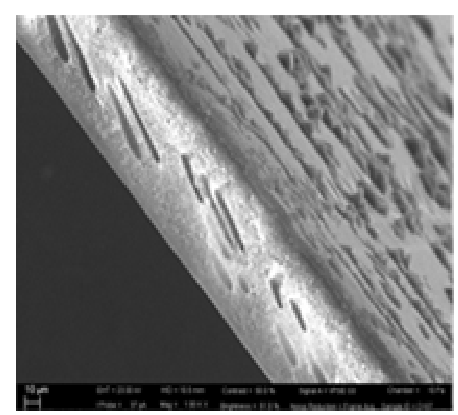

Membrane A

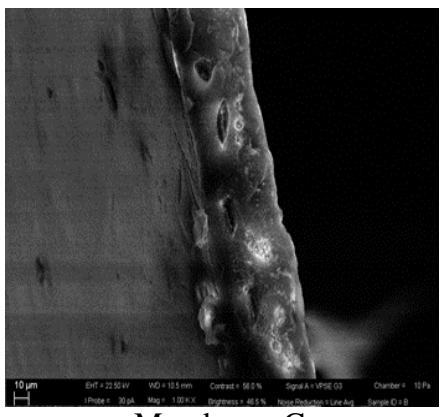

Membrane C

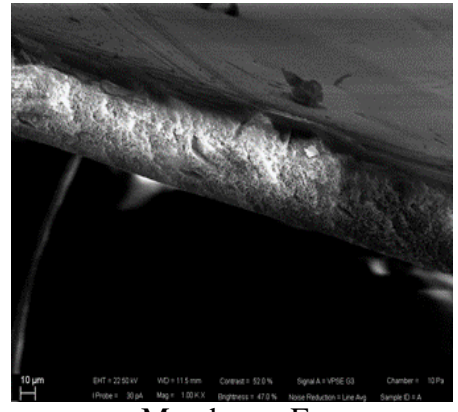

Membrane E 


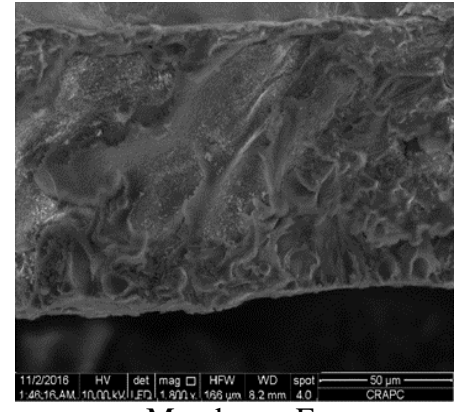

Membrane F

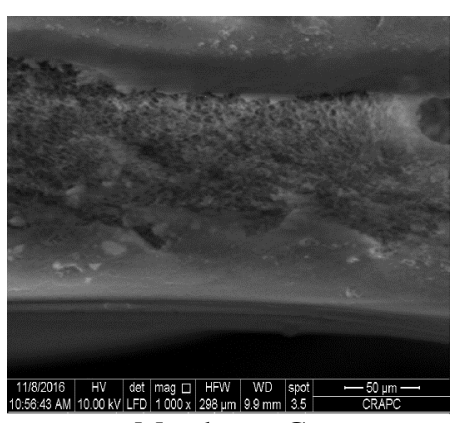

Membrane G

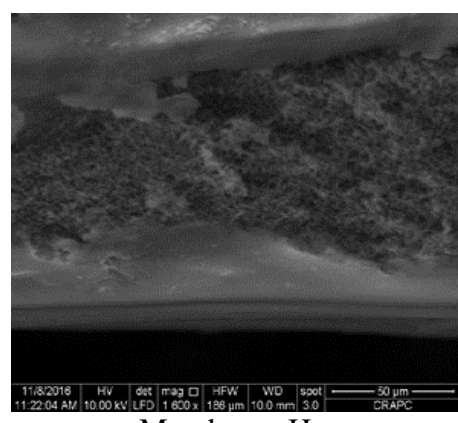

Membrane $\mathrm{H}$

Figure 6: SEM images of membranes

We concluded that membranes $\mathrm{MC}$ and $\mathrm{MF}$ can be classified as nanofiltration membranes, while the other membranes (ME, MG and MH) have a dense skin layer, followed by a highly porous intermediate layer, and therefore they can be classified as candidates for RO desalination membranes.

\section{Mechanical resistance}

Several studies have shown that cellulose acetate has very low mechanical properties, a tensile index of the order of $31 \mathrm{Mpa}$ and an elongation that does not exceed $13 \% .^{54}$ Considering this, we introduced the polysulfone, which has very high mechanical strength in order to improve the mechanical behavior of the membranes prepared from cellulose acetate. ${ }^{55}$

Figure 7 illustrates the effect of the membrane composition on the mechanical properties. The analysis of the mechanical properties gives very interesting data concerning Young's modulus. Young's modulus increases as the polysulfone ratio increases in the blend. The maximum value is $217.5 \mathrm{~N} / \mathrm{mm}^{2}$, with an elongation of $25 \%$ for the mixture that contained 25\% PSf.

Furthermore, we also note that the elongation at break decreases for membranes E, F, G, having a low PSf/PEG ratio and a higher concentration of acetate cellulose. A similar behavior was observed by Bai et al. ${ }^{54}$ for membranes prepared from cellulose acetate and PEG 600. They explained that this is due to the intrinsic phase equilibrium relationship of the solution, which has been modified by adding PEG. This has improved the affinity between the casting solution and the coagulation bath and thus the phase separation process has been accelerated, giving rise to the formation of a porous structure and consequently the mechanical strength decreases.
It is concluded that the incorporation of polysulfone in cellulose acetate improves the mechanical strength. The MC membrane shows a higher Young's modulus, as well as elongation at break, and therefore has the best mechanical properties, while MG has the lowest mechanical properties. The mechanical properties decrease in the following order: $\mathrm{MC}>\mathrm{MA}>\mathrm{MH}>\mathrm{MF}>\mathrm{ME}$ $>$ MG.

\section{Membrane performance \\ Effect of operating pressure (flux, contact angle, water content)}

The permeate flux is a graph of the pure water flux $\left(\mathrm{L} / \mathrm{m}^{2} \mathrm{~h}\right)$ as a function of the applied pressure (bar). As transmembrane pressure increases, the flow generally increases. ${ }^{49}$ Figure 8 below shows a relatively low flux, which does not exceed 17 $\mathrm{L} / \mathrm{m}^{2} \mathrm{~h}$ at 20 bar for membranes $\mathrm{G}, \mathrm{H}$, which is due to the high levels of CA. These results are in accordance with SEM observations, as when the structural morphology is dense, the flow is low. On the other hand, a significant increase in flux was observed for membranes $\mathrm{A}$ and $\mathrm{C}$, rising from $8.5 \mathrm{~L} / \mathrm{m}^{2} \mathrm{~h}$ to $75.4 \mathrm{~L} / \mathrm{m}^{2} \mathrm{~h}$ for membrane A and from $12.47 \mathrm{~L} / \mathrm{m}^{2} \mathrm{~h}$ to $87.3 \mathrm{~L} / \mathrm{m}^{2} \mathrm{~h}$ for membrane $\mathrm{C}$.

It was found that the PSf/PEG ratio in the membranes influences the total flux, when it is less than or equal to unit, the flux is very weak. For a ratio between 1.5 and 2, the flux is 5.5 times greater; this is the case for membranes $\mathrm{A}$ and $\mathrm{C}$. This increase in flux is due, on the one hand, to the presence of PSf and PEG, which contribute to the formation of larger aggregative pores of resultant blend membrane segments. ${ }^{24}$ Similar results have also been reported for the incorporation of PVP as an additive for PSf membranes. ${ }^{40,56}$ 
On the other hand, the hydrophilic nature of the PEG additive promotes the formation of pores for a weight of less than $12 \%$, thus the thermodynamic properties favor instantaneous demixing and a membrane with a porous surface layer is formed. However, we have reported that the addition of PEG can induce the enlargement of macrovoids in the membrane, as well as a significant increase in membrane permeability. ${ }^{41,57}$

Concerning membrane $\mathrm{F}$, the flux remains low for a ratio of PSf/PEG $=10 / 15 \quad(=0.66)$. According to several works, ${ }^{33}$ it can produce the opposite effects when the molecular weight of PEG exceeds the threshold of $12 \%$. The rheological impact becomes significant, the demixing of the solution film is delayed and the flux of the permeate decreases rather than increases, which reveals that the thermodynamic improvement is exceeded by the rheological obstacle to the demixing of the solution. ${ }^{32,58}$

Contact angle and water absorption studies were performed to investigate the hydrophilic

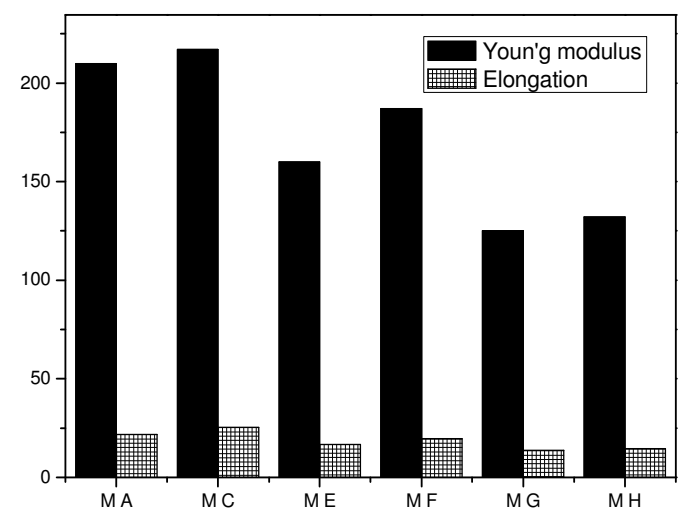

Figure 7: Mechanical properties of prepared membranes

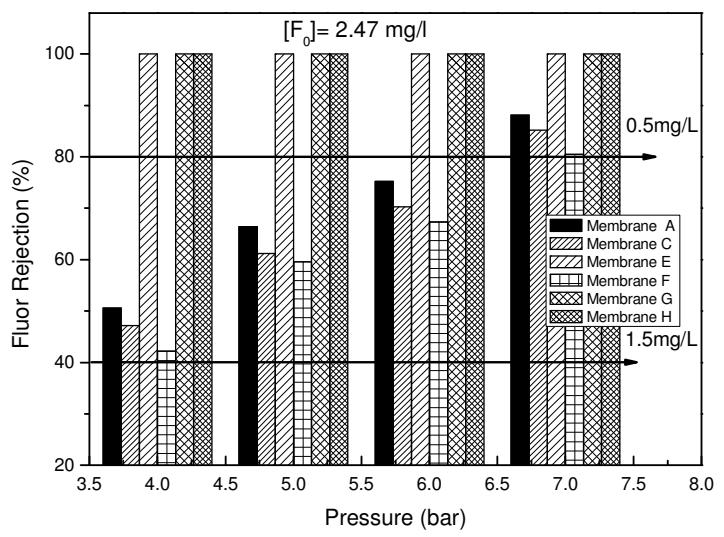

character, roughness and porosity of the membrane surface. It can be seen from Table 3 that the contact angle decreased by increasing the amount of PEG. It reaches the lowest contact angle for the mixture containing $12 \%$ by weight of PEG. Increasing the amount of PEG in the mixture increases the hydrophilic character of the membrane because the $\mathrm{CH} 2-\mathrm{OH}$ groups existing in the PEG structure, on the surface of the membrane, interact with water via the Van der Waals forces and hydrogen bonds, ${ }^{59}$ so the wettability increases.

Generally, the incorporation of PEG concentrations lower than $12 \%$ into the casting solution decreases contact angle, increases the water content, increasing hydraulic permeability and decreasing the resistance of the membrane. ${ }^{60}$ The highest water uptake was $76 \%$ and the minimum was $64 \%$. Membrane $\mathrm{C}$, with $12 \%$ PEG and $25 \%$ PSf, showed the maximum water absorption.

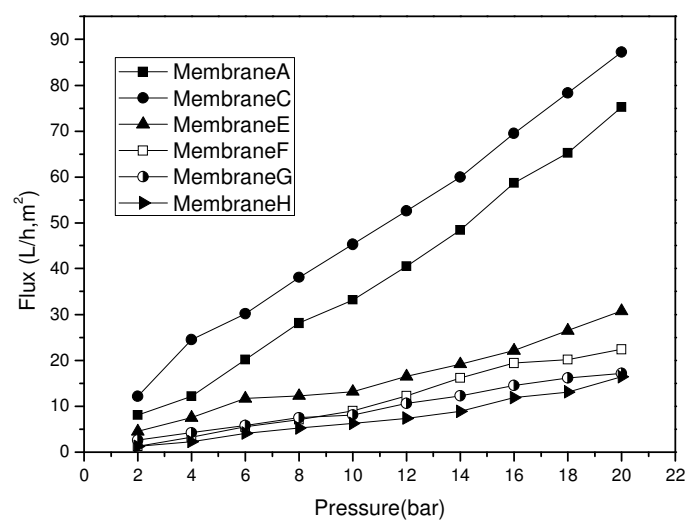

Figure 8: Effect of pressure on flux values of membranes

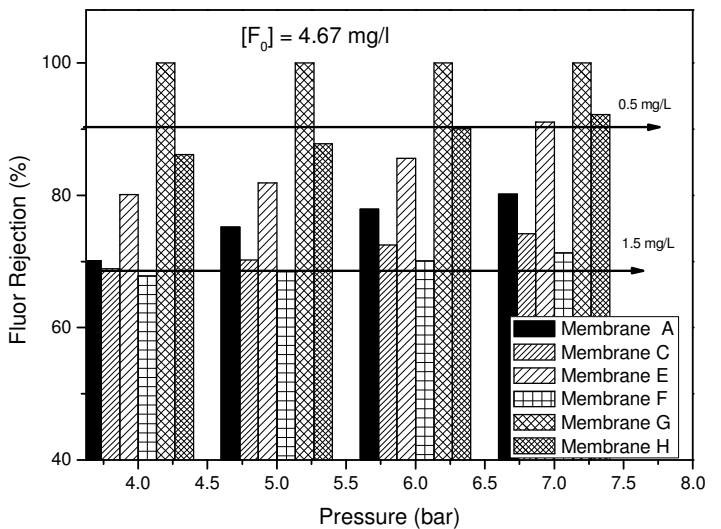


Cellulose acetate

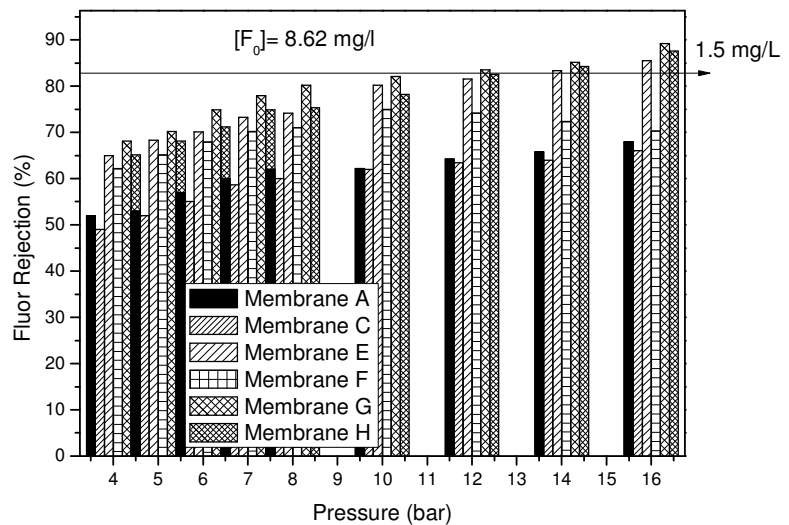

Figure 9: Rate of fluoride ion removal as a function of pressure (bar)

Table 3

Retention rate $T_{R}$ of fluoride ion corresponding to WHO requirements

\begin{tabular}{lccc}
\hline Retention rate $\mathrm{T}_{\mathrm{R}}(\%)$ & $\mathrm{F}_{0}=2.47 \mathrm{mg} / \mathrm{L}$ & $\mathrm{F}_{0}=4.67 \mathrm{mg} / \mathrm{L}$ & $\mathrm{F}_{0}=8.62 \mathrm{mg} / \mathrm{L}$ \\
\hline $\mathrm{F}=0.5 \mathrm{mg} / \mathrm{L}$ & $80 \%$ & $90 \%$ & $94 \%$ \\
$\mathrm{~F}=1.5 \mathrm{mg} / \mathrm{L}$ & $40 \%$ & $68 \%$ & $82.5 \%$
\end{tabular}

\section{Fluoride rejection}

Fluoride-rich solutions with initial concentration of sodium fluoride NAF, varying from 3.5 to $8 \mathrm{mg} / \mathrm{L}$, were prepared. The measured fluoride content was $2.47,4.67$ and $8.62 \mathrm{mg} / \mathrm{L}$, respectively. Figure 9 presents the elimination rate of fluoride ions as a function of the pressure. It was noted that the fluoride concentration decreases by increasing the pressure for all the membranes. In addition, the fluoride concentration required by WHO is in the range of 0.5-1.5 $\mathrm{mg} / \mathrm{L}$. The fluorine retention rate corresponding to this range is illustrated in Table 3.

In the case of $F_{0}=2.47 \mathrm{mg} / \mathrm{L}$, all the membranes allowed the removal of fluoride at low pressures. The rejection rate obtained for membrane films A, C and F is in accordance with the standard norm imposed by WHO at low pressures, not exceeding 7 bar, while membranes $\mathrm{E}, \mathrm{G}$ and $\mathrm{H}$ have fluoride rejection rates greater than $0.5 \mathrm{mg} / \mathrm{L}$ at different pressures, close to $100 \%$.

At the initial concentration of $\mathrm{F}_{0}=4.67 \mathrm{mg} / \mathrm{L}$, a good retention was obtained at pressures above 4 bar, the rejection rate being the highest for membranes $\mathrm{G}$ and $\mathrm{H}$, of $97.0 \%$ and $94.9 \%$, respectively. Membranes $\mathrm{A}$ and $\mathrm{C}$ have acceptable fluoride removal rates, around $70 \%$ and the lowest retention is observed for membrane $\mathrm{F}$ for pressures $\leq 6 \mathrm{bar}$. Therefore, this confirms that the increase of PEG in the mixture improves the total flux and reduces the fluoride retention for PEG concentrations of less than or equal to $12 \%$.

It has been found that for an initial fluorine concentration $F_{0}=8.62 \mathrm{mg} / \mathrm{L}$, and for a pressure range of 2-8 bar, the maximum fluoride removed is $82.1 \%$ for membrane $\mathrm{G}$ and the minimum of $62 \%$ for membrane $\mathrm{C}$, which are below the standard norms recommended by WHO. It is in this context that we decided to increase the applied pressure up to 16 bar to evaluate the elimination of the fluoride ion, the results of the retention obtained are in agreement with WHO standards for membranes $\mathrm{E}, \mathrm{G}$ and $\mathrm{H}$. The retention reaches the value of $89.2 \%$ for membrane $\mathrm{G}$ at 16 bar. This membrane contains the highest ratio in molecular weight of cellulose acetate, in the absence of PEG additive. The increase in the CA concentration causes a significant increase in the viscosity values, the mutual diffusion between the non-solvent (water) and the solvent (DMF) is greatly reduced in the system during the solidification of the casting solution. Consequently, when the amount of CA increases, the precipitation takes longer to stop, which leads to the preparation of thinner and denser membranes. ${ }^{30}$ In fact, small pores lead to low flux and better selectivity.

We may conclude that, firstly, fluorine rejection decreased by increasing the fluoride concentration and as the fluorine concentration increased, the pressure increased, leading to 
decreased rejection. Meanwhile, the rejection increased with increasing operating pressure at the same feed concentration. ${ }^{52}$ Secondly, the rejection varies inversely with the flux, while membrane morphology and the heat treatment improved the rejection, and affected the flux.

This study showed that the retention of fluoride ion varies in the following order: $\mathrm{G}>\mathrm{H}>$ $\mathrm{E}>\mathrm{A}>\mathrm{C}>\mathrm{F}$ at different pressures. Membranes
$\mathrm{G}$ and $\mathrm{H}$ give a defluoridation greater than 0.5 $\mathrm{mg} / \mathrm{L}$. These results are good, but not satisfactory, because lack of fluoride causes dental caries, moreover, the presence of fluoride traces in water is essential to health. Therefore, it is clear that the optimal rejection is recorded for membranes A and $\mathrm{C}$, for an initial fluorine concentration of less than or equal to $4.67 \mathrm{mg} / \mathrm{L}$.
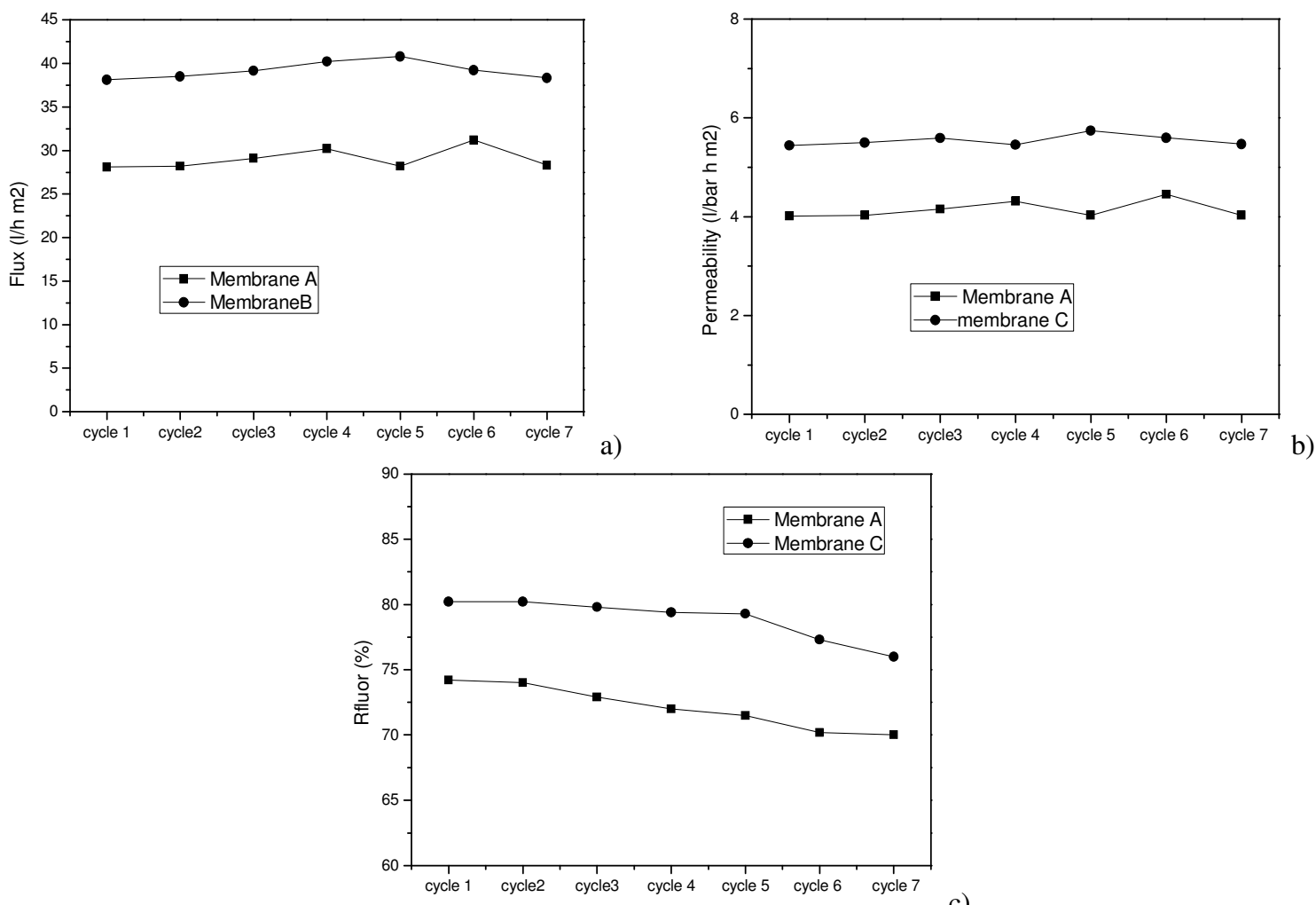

c)

Figure 10: Flux (a), permeability (b) and fluoride rejection (c) at pressure of 7 bar for membrane $\mathrm{A}$ and membrane C for several filtration cycles

\section{Membrane durability}

The efficiency of a membrane can decrease over time and after several uses, the effectiveness of the membrane may be impaired. Therefore, we carried out several filtration cycles on the same membrane film at a pressure of 8 bar. These tests were applied for membranes $\mathrm{A}$ and $\mathrm{C}$, because they presented the best flux, good permeability, the highest mechanical resistance and a very satisfactory fluoride rejection for an initial fluorine concentration of $4.67 \mathrm{mg} / \mathrm{L}$. This concentration was selected so as to correspond to most fluoride ion rich water recorded in southern Algeria (see Table 1). After each filtration cycle, washing with distilled water was carried out for a period of time. The rejection rate, the flux as well as the permeability are presented in Figure 10.

The obtained results are very satisfactory, the rate of fluoride rejection decreased by only $5 \%$ after 7 cycles of treatment. The flux and the permeability were stable and almost constant, being of $29.04 \mathrm{~L} / \mathrm{m}^{2} \mathrm{~h}$ and $4.14 \mathrm{~L} / \mathrm{m}^{2} \mathrm{hbar}$, respectively, for membrane A. The same behavior was observed for membrane $\mathrm{C}$, with the flow and permeability of $39.18 \mathrm{~L} / \mathrm{m}^{2} \mathrm{~h}$ and $5.59 \mathrm{~L} / \mathrm{m}^{2} \mathrm{hbar}$, respectively. This allows concluding that the membranes were not clogged for this initial concentration $F_{0}=4.67 \mathrm{mg} / \mathrm{L}$ and for a pressure of 8 bar after several uses. 


\section{CONCLUSION}

In this work, membrane films, containing PSf/AC dissolved in DMF as a solvent and PEG as additive, were prepared by the phase inversion method. The membrane structure was affected by several factors, such as annealing treatment and PSf/PEG ratio in the casting solution. The results obtained are described below.

- The thermal stability of the membranes was examined by ATG/DSC. Three massive degradation stages were observed by ATG. The first was observed at $200{ }^{\circ} \mathrm{C}$, this shows that the membranes developed have very good thermal resistance. A single Tg by DSC indicates the presence of PSf and CA in the mixture and confirms the existence of an interaction between these constituents, thus reflecting their miscibility. - FTIR analyses show the existence of the characteristic band of PEG at $691 \mathrm{~cm}^{-1}$, the displacement of the bands observed at $1223 \mathrm{~cm}^{-1}$ and $1730 \mathrm{~cm}^{-1}$, characterizing cellulose acetate groups, towards higher wavenumbers indicates the presence of new bonds between the mixture components. IR spectra are in agreement with the thermal analysis results.

- SEM results suggest that the annealing treatment modifies and improves the surface of the membrane. The surface layers of the membrane become denser and smooth, and the intermediate layer is porous for a concentration of $90 \%$ CA. On the other hand, the increase of the $\mathrm{PSf} / \mathrm{PEG}$ ratio in the mixture leads to the formation of macrovoids and, consequently, the membranes exhibit higher flux permeation.

- In the mechanical strength test, membrane MC, containing 25\% PSf, shows higher mechanical resistance for Young's modulus of $217.5 \mathrm{~N} / \mathrm{mm}^{2}$ with $25 \%$ elongation.

- A significant flux increase was observed for membranes $\mathrm{A}$ and $\mathrm{C}$, increasing from $8.5 \mathrm{~L} / \mathrm{m}^{-2} \mathrm{~h}$ to $75.4 \mathrm{~L} / \mathrm{m}^{-2} \mathrm{~h}$ for membrane A and from 12.47 $\mathrm{L} / \mathrm{m}^{-2} \mathrm{~h}$ to $87.3 \mathrm{~L} / \mathrm{m}^{-2} \mathrm{~h}$ for membrane C. We find that the PSf/PEG ratio in the membranes affects the total flux, when it is less than or equal to unit, the flux is very weak.

- The optimal fluoride rejection is obtained for membranes $\mathrm{A}$ and $\mathrm{C}$ for an initial concentration equal to or less than $4.25 \mathrm{mg} / \mathrm{L}$ and it is in accordance with WHO standards.

- For an initial fluoride concentration equal to $8.62 \mathrm{mg} / \mathrm{L}, \mathrm{G}$ and $\mathrm{H}$ membranes gave a satisfactory removal rate, according to WHO, for pressures exceeding 10 bar, but the recorded flux is very low.
- Membranes A and C were selected to investigate the durability test of the membrane, their performance was constant and stable for 7 filtration cycles.

- Membrane C proved to be the best choice, as evidenced by its highest mechanical resistance, the best flow, a percentage of fluorine rejection satisfactory for an initial fluoride concentration characteristic of southern Algerian water.

\section{REFERENCES}

1 M. Amini, K. Mueller, K. C. Abbaspour, T. Rosenberg, M. Afyuni et al., Environ. Sci. Technol., 42, 3662 (2008), http://dx.doi.org/10.1021/es071958y

2 WHO for Drinking-Water Quality, $4^{\text {th }}$ ed., 2011, p. 370, https://apps.who.int/iris/handle/10665/44584

3 N. Arlappa, I. Q. Aatif and R. Srinivas, Int. J. Res. Dev. Health, 1, 97 (2013), https://www.feingold.org/Research/PDFstudies/Arlapp a2013.pdf

Y. Wang, X. Zhang, Z. Zhao and H. Xu, Biol. Trace Elem. Res., 176, 367 (2016), http://dx.doi.org/10.1007/s12011-016-0833-x

5 M. Bennajah, B. Gourich, A. Essadki, H. Vial and H. Delmas, Chem. Eng. J., 148, 122 (2009), http://dx.doi.org/10.1016/j.cej.2008.08.014

6 J. A. Camargo, Chemosphere, 50, 251 (2003), http://dx.doi.org/10.1016/s0045-6535(02)00498-8

7 D. Saoud, Doctoral Thesis, University of Ouargla, Ouargla, Algeria, 2009 , http://hdl.handle.net/123456789/641

8 A. Ben Nasr, Doctoral Thesis, University of Sfax, Sfax, Tunisia, 2013, https://tel.archives-ouvertes.fr/tel01045117/document

9 L. Youcef and S. Achour, Courrier du Savoir, 01, $65 \quad$ (2001), http://revues.univbiskra.dz/index.php/cds/issue/view/259

10 P. Dhanasekaran, P. M. Satya Sai, C. Anandbabu and K. K. Rajan, Water Sci. Technol.: Water Supply, 16, 1297

(2016),

http://dx.doi.org/10.2166/ws.2016.032

${ }_{11}$ P. Krzysztof, K. Henrik, T. Madsen and G. Erik, Water Sci. Technol.: Water Supply, 14, 532 (2014), http://dx.doi.org/10.2166/ws.2014.094

12 J. Kheriji and B. Hamrouni, Water Sci. Technol.: Water Supply, 16, $684 \quad$ (2015), http://dx.doi.org/10.2166/ws.2015.178

13 E.-S. Kim, S. Dong, Y. Liu and M. Gamal El-Din, Water Sci. Technol., 68, $2668 \quad$ (2013), http://dx.doi.org/10.2166/wst.2013.533

14 M. Pontie, H. Buisson, C. K. Diawara and H. E. Tome, Desalination, 157, $127 \quad$ (2003), http://dx.doi.org/10.1016/s0011-9164(03)00391-6

15 C. K. Diawara, S. M. Lo, M. Rumeau, M. Pontie and O. Sar, J. Membrane Sci., 219, 103 (2003), http://dx.doi.org/10.1016/s0376-7388(03)00189-3 
16 A. Lhassani, M. Rumeau, D. Benjelloun and M. Pontie, Water Res., 35, 3260 (2001), http://dx.doi.org/10.1016/s0043-1354(01)00020-3

17 F. V. Adams, E. N. Nxumaloa, R. W. M. Krause, E. M. V. Hoek and B. Mamba, J. Membrane Sci., 405, 291

(2012), http://dx.doi.org/10.1016/j.memsci.2012.03.023

18 R. Kaveh, Z. Shariatinia and A. Arefaza, Water Sci. Technol:: Water Supply, 16, 1378 (2016), http://dx.doi.org/10.2166/ws.2016.059

19 A. Akbari, V.-R. Abbaspour and S. Rostami, Water Sci. Technol., $\quad \mathbf{7 4 ,} 333 \quad$ (2016), http://dx.doi.org/10.2166/wst.2016.192

20 S. R. Panda and S. De, Desalination, 347, 52 (2014), http://dx.doi.org/10.1016/j.desal.2014.05.030

21 B. M. Ganesh, A. M. Isloor and A. F. Ismail, Desalination, $\quad 313, \quad 199 \quad$ (2013), http://dx.doi.org/10.1016/j.desal.2011.09.047

22 T. Savart, Doctorat Thesis, Toulouse University, Toulouse, France, 2013, http://www.theses.fr/2013TOU30315

23 M. H. Abdullah, L. P. Manríquez, T. Puspasari, C. A. Scholes, S. E. Kentish et al., J. Membrane Sci., 9, 042

http://dx.doi.org/10.1016/j.seppur.2018.06.074

24 K. A. Gebru and C. Das, J. Environ. Manage., 217, 600

http://dx.doi.org/10.1016/j.jenvman.2018.03.131

25 G. Jonsson and C. Boesen, Desalination, 17, 145 (1975), http://dx.doi.org/10.1016/s00119164(00)88071-6

26 R. Haddad, E. Ferjani, M. S. Roudesli and A. Deratani, Desalination, 167, 403 (2004), http://dx.doi.org/10.1016/j.desal.2004.06.154

27 Q. Kutowy and S. Sourirajan, J. Appl. Polym. Sci., 19 , 1449

(1975),

http://dx.doi.org/10.1002/app.1975.070190525

28 J. Garcia-Ivars, M. I. Alcaina-Miranda, M. I. Iborra-Clar, J. A. Mendoza-Roca and L. PastorAlcañiz, Separ. Purif. Technol., 128, 45 (2014), http://dx.doi.org/10.1016/j.seppur.2014.03.012.

29 S. Zhang, K. Y. Wang, T. S. Chung, H. Chen, Y. Jean et al., J. Membrane Sci., 360, 522 (2010), http://dx.doi.org/10.1016/j.memsci.2010.05.056

30 J. Zyaie, M. Sheikhi, J. Baniasadi, S. Sahebi and T. Mohammadi, Chem. Eng. Technol., 10, 1002 (2018), http://dx.doi.org/10.1002/ceat.201800084

31 M. Sivakumar, D. R. Mohan and R. Rangarajan, J. Membrane Sci., 268, $208 \quad$ (2006), http://dx.doi.org/10.1016/j.memsci.2005.06.017

32 P. T. P. Aryanti and K. I. G. Wenten, J. Water Sustain., 2, 85 (2013), www.academia.edu/7910400

33 M. Homayoonfal, A. Akbari and M. R. Mehrnia, Desalination, 263, 217 (2010), http://dx.doi.org/10. 1016/j.desal.2010.06.062

34 J. E. Yoo, J. H. Kim and Y. Kim, J. Membrane Sci., 216, 95 (2003), http://dx.doi.org/10.1016/S03767388(03)00062-0
35 I. Genne, S. Kuypers and R. Leysen, J. Membrane Sci., 61, 334 (1996), http://dx.doi.org/10.1016/03767388(95)00132-8

36 K. J. Kim, G. Chowdhury and T. Matsuura, J. Membrane Sci., 179, $43 \quad$ (2000), http://dx.doi.org/10.1016/0376-7388(95)00132-8

37 N. Munirah, A. M. Mazira, M. T. Ramlah and A. Sharifah, Key Eng. Mater., 594, 281 (2014), http://dx.doi.org/10.4028/www.scientific.net/kem.594595.281

38 A. Akbari, S. Desclaux, J. C. Remigy and P. Aptel, Desalination, $\quad 149, \quad 101 \quad$ (2001), http://dx.doi.org/10.1016/s0011-9164(02)00739-7

39 B. M. Ganesh, A. M. Isloor and M. Padaki, Desalination, 287, $103 \quad$ (2012), http://dx.doi.org/10.1016/j.desal.2011.09.047

${ }_{40}$ M. Sivakumar, D. R. Mohan, R. Rangarajan and Y. Tsujita, Polym. Int., 54, $956 \quad$ (2005), http://dx.doi.org/10.1002/pi.1798

${ }_{41}$ M. Sivakumar, L. Susithra, D. R. Mohan and R. Rangarajan, J. Macromol. Sci. A: Pure Appl. Chem., 43, 1541

(2006),

http://dx.doi.org/10.1080/10601320600896819

42 A. A. Said and Mustafa, IOP Conference Series Materials Science and Engineering, TALENTA-CEST 2017, Sumatera Utara, Indonesia, 7-8 September 2017, published in 2018, vol. 309, p. 12, http://dx.doi.org/10.1088/1757-899X/309/1/012122

43 D. Bhongsuwan and T. Bhongsuwan, Nat. Sci., 42, 311

(2008),

http://kasetsartjournal.ku.ac.thkujfiles/2009/A0903191 536448750.pdf

T. D. Kusworo, N. Aryanti, M. M. H. Firdaus and H. Sukmawati, Am. Inst. Phys., 1699, 040014 (2015), http://dx.doi.org/10.1063/1.4938329

${ }_{45}$ M. Mohapatra, S. Anand, B. K. Mishra, D. E. Giles and P. Singh, J. Environ. Manage., 91, 67 (2009), http://dx.doi.org/10.1016/j.jenvman.2009.08.015

${ }^{46}$ Z. Z. Ismail and H. N. Abdel Kareem, Waste Manage.,45, 66 (2015), http://dx.doi.org/10.1016/j.wasman.2015.06.039

47 C. B. Dissanayake, Int. J. Environ. Stud., 19, 195 (1991),

http://dx.doi.org/10.1080/00207239108710658

${ }^{48}$ K. Venugopal and S. Dharmalingam, Desalination, 296, $37 \quad$ (2012), http://dx.doi.org/10.1016/j.desal.2012.04.006

49 N. Ghaemi, S. S. Madaeni, A. Alizadeh, P. Daraei et al., Separ. Purif. Technol., 96, 214 (2012), http://dx.doi.org/10.1016/j.seppur.2012.06.008

50 B. Zhao, C. P. Huang, S. Chen, Y. Wang and D. S. Li, Water Sci. Technol.: Water Supply, 11, 668 (2011), http://dx.doi.org/10.2166/ws.2011.094.

51 H. Tayeb, Doctoral Thesis, Science University of Tlemcen, Tlmcen, Algeria (2013), http://dspace.univtlemcen.dz/bitstream/112/6294/1/acetate-de-celluloseversion-finale.pdf 
52 A. El-Gendi, H. Abdallah, A. A. Shereen and K. Amin, J. Mol. Struct., 5, $122 \quad$ (2017), http://dx.doi.org/10.1016/j.molstruc.2017.05.122

53 A. El-Gendi, A. Deratani, S. A. Ahmed and S. S. Ali, Egypt. J. Petrol., 5, 3 (2014), http://dx.doi.org/10.1016/j.ejpe.2014.05.003

54 H. Bai, Y. Zhou, X. Wang and L. Zhang, Proc. Environ. Sci., 16, $346 \quad$ (2012), http://dx.doi.org/10.1016/j.proenv.2012.10.049

55 V. Ghaffarian, S. M. Mousavia and M. Bahreini, Desalin. Water Treat., 54, $473 \quad$ (2014), http://dx.doi.org/10.1080/19443994.2014.883329

56 J. R. H. Wang, S. H. Koo, J. H. Kim, A. Higuchi and T. M. Tak, J. Appl. Polym. Sci., 60, 1343 (1996), http://dx.doi.org/10.1002/(sici)10974628(19960531)60:9<1343::aid-app9>3.0.co;2-j

57 Q. J. Jun, W. Fook-Sin, L. Ying and L. Yu-Tie, $J$. Membrane Sci., 211, $139 \quad$ (2003), http://dx.doi.org/10.1016/s0376-7388(02)00415-5

58 M.-J. Han, J. Membrane Sci., 202, 55 (2002), http://dx.doi.org/10.1016/s0376-7388(01)00718-9

59 M. M. Pendergast and E. M. V. Hoek, Energ. Environ. Sci., 4, $1946 \quad$ (2011), http://dx.doi.org/10.1039/c0ee00541j

60 S. Gassara, W. Chinpa, D. Quemener, R. Ben Amar and A. Deratani, J. Membrane Sci., 436, 36 (2013), http://dx.doi.org/10.1016/j.memsci.2013.02.005 